\title{
Um estudo prospectivo sobre cadeira de rodas para pacientes com ela
}

\section{Adriana N Klein ${ }^{1}$, Monica Omori², Pedro H Almeida}

1.Terapeuta Ocupacional responsável pelo Ambulatório de TO em ELA do Setor de Doenças Neuromusculares da UNIFESP / EPM

2.TO Monica Omori, Especialista em Reabilitação Física

A esclerose lateral amiotrófica (ELA) é uma doença neurodegenerativa decorrente da perda de neurônios localizados no córtex cerebral, tronco cerebral e corno anterior da medula espinhal. Manifesta-se pela fraqueza muscular progressiva, atrofia, espasticidade, disartria e comprometimento da musculatura respiratória.

Com o surgimento do desequilíbrio muscular de tronco e membros há conseqüente comprometimento da mobilidade comunitária e domiciliar, no qual resultam em quedas frequientes, restringem o desempenho funcional para as atividades de vida diária e comprometem a vida social do paciente.

O momento mais adequado para o início do uso de cadeira de rodas começa quando o paciente perde a capacidade para caminhar com segurança em ambientes externos, assim a cadeira de rodas funciona como um auxiliador da locomoção, evitando um gasto energético excessivo, aumentando o conforto e mantendo a rotina de vida social e ou ocupacional.

Há vários tipos de cadeira de rodas no mercado brasileiro, alguns modelos são mais específicos para pacientes com ELA. Por isto torna-se importante consultar um profissional da reabilitação com experiência, para prescrição do modelo e tamanho mais adequado.

Existem poucas políticas públicas de concessões de cadeiras de rodas, e também o sistema privado de saúde não financia cadeira de rodas de boa qualidade.

O objetivo deste estudo foi acompanhar o processo de aquisição de cadeira de rodas adequada desde o momento que este paciente recebe a prescrição da mesma. 
Os pacientes com diagnóstico de ELA confirmado e em investigação do ambulatório de doença do neurônio motor do setor de doenças neuromusculares da UNIFESP foram avaliados pela equipe de terapia ocupacional. Receberam prescrição de uma cadeira de rodas adequada e eram reavaliados a cada 3 meses.

Neste reavaliação foi verificado se o paciente havia adquirido a cadeira de rodas prescrita, o tempo para este processo e a forma de aquisição.

No estudo participaram 39 indivíduos (37 com diagnóstico definido de ELA e 02 ainda sem diagnóstico definido), sendo 27 homens e 12 mulheres, com média de idade de 54,84 anos e tempo médio de diagnóstico de 18,9 meses. O tempo médio de espera entre o fechamento do diagnóstico e a obtenção da primeira prescrição da cadeira de rodas foi de 23,84 meses. Foram prescritas vinte e duas cadeiras com sistema reclinável de encosto e apoios de pés, catorze cadeiras de rodas sem sistema reclinável de encosto e apoios de pés, e três pacientes já possuíam cadeira de rodas de modelo adequado. Cinco participantes do estudo necessitaram de prescrição para sistema de adequação postural e a média de espera entre ao fechamento do diagnostico e a sua prescrição foi de 32,4 meses.

Dos 36 pacientes que receberam a prescrição, 15 não retornaram para reavaliação, 09 pacientes conseguiram a cadeira de rodas via doação da ABRELA, 06 pacientes compraram de forma particular, 03 conseguiram doação via Prefeitura Municipal, 02 receberam doação via DMR-HC, e 01 via doação do Lar Escola São Francisco.

O presente estudo evidencia uma média de tempo extensa entre o fechamento de diagnóstico e a prescrição de um modelo de cadeira adequado. Há necessidade de equipe de reabilitação acompanhe a dificuldade de locomoção para prescrição da cadeira no momento mais adequado. Não percebemos políticas públicas de saúde para 


\section{SIMPÓSIO BRASILEIRO DE DNM/ELA}

viabilizar a doação de equipamento para o paciente com ELA, e também nenhum dado referente a aquisição de equipamento via sistema privado de saúde, e sim financiado pelos próprios familiares. Percebe-se o importante papel da ABRELA para o repasse de cadeiras de rodas recebidas via doação de familiares. Sugerimos a criação de propostas como o projeto de LEI 260/03 que propõe políticas de doações de cadeira de rodas para pacientes que não possuem condições financeiras para aquisição. Conclusão: As prescrições de cadeira de rodas adequadas para pacientes de ELA pode ser considerada tardia, por meio deste estudo. Sabe-se que uma cadeira de rodas adequada faz parte do tratamento do paciente com ELA podendo atuar no desequilíbrio muscular, melhorar o conforto, a segurança e ampliar a possibilidade de acesso fora do ambiente domiciliar, influenciando positivamente na qualidade de vida. 